\title{
Students' Use of Graphs in Understanding the Concepts of Derivative
}

\author{
Haliza Abd Hamid ${ }^{1}$, Noraini Idris ${ }^{2}$ and Ruzela Tapsir ${ }^{3}$ \\ ${ }^{1,3}$ Fakulti Sains Komputer dan Matematik, Universiti Teknologi MARA, Shah Alam, Selangor, \\ Malaysia. \\ ${ }^{2}$ National STEM Association, Malaysia. \\ halizahamid@tmsk.uitm.edu.my
}

\begin{abstract}
Previous research showed that visual utilisation in mathematics classrooms help students in understanding concepts. This study was conducted to assist educators in realising visual reasoning skills in students which can be employed in classroom practices as the students move to their higher levels of education. The study is part of a larger project. It studied 194 pre-university students' perception of the use of graphs and examined their actual ability to extract information embedded in the graphs in order to understand and solve derivative problems. Findings showed that students were very encouraged to use graphs in the teaching and learning of mathematics but the opposite was evident in their worked solutions. Implications of teaching and learning are also discussed.
\end{abstract}

Keywords: Derivative, graphs, mathematics education, visual reasoning.

\section{Introduction}

Conceptually, the role of visual thinking is so fundamental to the understanding of calculus that it is difficult to imagine a successful calculus course which does not emphasise the visual elements of the subject (Zimmerman, 1991, p.136).

Zimmerman's statement on the use of visual elements as a tool to understand calculus and mathematics and solve mathematical problems has diverted the trend of researchers, educators and mathematicians internationally towards the development of visual reasoning skills. The development of students' abilities in visual reasoning is important in mathematics education. In fact, the mathematics education community seems to agree that learning mathematics and calculus in particular, through symbolic manipulations based on given formulae are meaningless. In mathematics, problems are solved through the process of extracting the required information from the visual elements followed by various mental processes before progressing to the operations. Schoenfeld (1992) advocated that students are to build their mathematical and conceptual knowledge through problem solving: 1) as additions to memorising steps and procedures, 2) by examining and investigating patterns as additions to memorising and, 3) by constructing formulae as additions to doing and practising exercises (Haapasalo \& Kadijevich, 2000). However, the development of such abilities has been empirically proven to be difficult for many students (Uesaka \& Manalo, 2011). Thus, rather than following a teacher's or a mathematician's ideas, educators, on the other hand, should focus more on the students' reasoning and try to venture deeper into and understand their minds and thinking, so as to subsequently encourage further development of their ideas and thoughts. The ideas of student centeredness and visual reasoning inspired this study as we aimed to acquire information upon students' perceptions and how they actually make use of graphs to reason in the process of finding solutions to the problems assigned. 
The calculus domain, specifically derivatives, is an essential and interesting mathematical topic taught at the upper secondary level with vast applications at the higher levels of education. Therefore, some educators in Malaysia, in an attempt to keep up with the efforts of the United States and Europe, had called for some adjustments to be made in the instructional methods for calculus (and mathematics). The Malaysian Higher Education Ministry introduced some initiatives to ensure that the proposed changes would answer these requests. These initiatives involved: the curriculum and methods of delivering materials; the promoting of comprehension (Ball, Hoyles, Jahnke \& Movshovitz-Hadar, 2002); and, the ability to understand calculus and mathematics through visual tools and reasoning (Hanna \& Jahnke, 1996; Stylanides, 2007). Students' ability to reason visually is crucial in the process of developing and valuing convincing arguments (Baker, Cooley \& Trigueros, 2000; Ubuz, 2007). Researchers and educators have also noted students' reluctance when practising visual reasoning in the classrooms (Ball et al., 2002). For example, although curriculum developers at the secondary and pre-university levels emphasised the use of technology such as graphics calculators which are graphical in nature, in the actual classroom environments, many teachers still reverted to the teaching of algorithms and procedures for solving mathematical problems.

Consequently, students were hindered from adopting visuals as a reasoning and solution tool. In addition, many students regard visual representations such as graphs, as one of the procedural steps to carry out without associating them with logical reasoning or justification for their solution steps (Kamii \& Dominck, 1998). Consequently, they proceeded to the higher levels of education not being fully-equipped with reasoning and critical thinking skills. Many difficulties have also been reported when students need to understand the concepts of functions and derivatives which are in fact central to the study of calculus. Further, little is known about how students, specifically in Malaysia, acquire the ability to relate the connections between the two concepts graphically.

This paper presents the results obtained from the investigation on pre-university students' perceptions of the use of graphs to solve mathematical problems and their actual ability to understand and reason with the connections between the properties of a function and its derivatives. It is part of a longer study to investigate the development of visual reasoning when solving derivative problems using the Cartesian graphs. Visual reasoning has been shown to be a vital ability in perceiving the behaviour of functions and interpreting related derivative properties. Therefore, the study aimed to focus on the following questions:

1. What are the students' perceptions of the use of graphs in the teaching and learning of mathematics?

2. To what extent are students able to employ graphs as visual information for reasoning in solving derivative problems?

3. Is there any correlation between the students' perception of the use of graphs and their actual utilisation of graphs in solving derivative problems?

\section{Theoretical Framework}

\section{Students' understanding of derivative}

Classroom teaching of differential calculus is mostly done based on textbook approaches and through rote learning. Students are exposed to the sequences of procedures and 
steps to differentiate diverse types of functions. Most of the students are well-versed with the procedural and algebraic relationships between functions and their derivatives. Subsequently, sketching the graphs of either the functions or their derivatives is also done using similar methods. In his thesis, Stahley (2011) identified and grouped students' understanding of derivatives into two categories; the 'point-wise' understanding and 'across-time' understanding. In the 'point-wise' understanding, students were able to identify the different types of stationary and inflexion points such as the local maxima, local minima, stationary inflexion or non-stationary inflexion, while in the 'across-time' understanding, the students were able to comprehend the graphical connection between a function and its derivative (Monk, 1994). Many research studies has been carried out focussed upon the students' abilities in understanding functions and their derivatives both algebraically and graphically (Asiala, Cottril, Dubinsky\& Swingendorf, 1997; Aspinwall, Shaw, \& Presmeg, 1997; Borgen \& Manu, 2002; Tiwari, 2007; Ubuz, 2007; Zandieh, 2000).

\title{
Visual Argument Hypothesis
}

After Orton's (1983)

\begin{abstract}
It is known that some students are introduced to differentiation as a rule to be applied without much attempt to reveal the reasons for and justifications of the procedure. Many regard this as bad educational practice, and, in fact, it should not be necessary (p.242),
\end{abstract}

There has been an increase in mathematics educational research highlighting the graphing aspects to understanding the concepts of calculus in the last four decades. Ratwani, Trafton, and Boehm-Davis (2008) stated that most theories on graphical comprehension focussed on the conceptual and perceptual processes specifically on the extraction of information embedded in graphs. Waller's (1981) Visual Argument characterised how graphics, specifically graphs, communicate their embedded information. According to the visual argument hypothesis, the effectiveness of graphics is based on visual-spatial properties and their advantage with fewer cognitive processing as compared to only text. More specifically, graphs communicate information through their individual elements and how the elements are arranged in space. Kosslyn (1994) outlined the structural components of graphs as the framework, the specifiers, the label and the background. The framework of an L-shape Cartesian graph such as axes and scales provide information on the types of data to measure and the measurements being used (Lohse, 1993). The specifiers, like the line or curve, represent the relationships among the data represented within the framework. Both legs are labelled with data to be measured and the specific measurements to be made. The title of the line or curve is considered as another type of label. The background of the graphs such as the grid or colours and pictures, in other types of graphs, helps in emphasising and making reading and interpretation of the data clearer. This perceptual enhancement (Larkin \& Simon, 1987) produced effective displays that make communication of information easier for students to perceive or infer based on the existing relationships of data.

Larkin and Simon (1987) developed production system models in order to understand the cognitive processes involved when students are working with graphs. Graphs provide computational advantage as compared to text alone as they assist students in retrieving and 
extracting information through the perceptual processes. In mathematical problem solving dealing with text alone, students need to read or browse through the entire text for relevant and important information before storing them in the working memory, while at the same time exploring for other relevant parts. The processes continue until all information is gathered in the working memory. Working memory is known for its limited capacity as it is unable to hold data for a long time. Therefore, these processes are prone to errors. Graphs, on the other hand, systematically organise information spatially making it easier to be read. Students may skip the process of storing data in the working memory because they are already visually available for them to retrieve and interpret.

This stance offers an explanation for the difficulties that students face and consequently commit errors when relating the properties of function and their derivative using graphs. Research that investigated students working with graphs on functions and their derivatives revealed that students complicate themselves between the slope of the chord and the slope of the tangent to the curve (Asiala et al., 1997; Tiwari, 2007; Ubuz, 2007). In total, they were unable to coordinate and relate the two different attributes of the function. A visual exhibiting of the connection of the two quantities is therefore designed in the form of graphs as tasks for the students.

\section{Methodology}

\section{Participants}

The participants were 194 pre-university students taking the South Australian Matriculation programme in Malaysia with the intention to pursue to various disciplines at the tertiary level. At the time of the study, the students had finished the syllabus on calculus. They were also exposed to the concepts and applications of derivatives for at least a year at the secondary level prior to joining the pre-university curriculum.

\section{Instrumentation}

Two types of data collection instruments were employed. The Visual Representation Usage Level (VRUL) was an adapted 17-Likert type questionnaire developed by Uesaka, Manalo and Ichikawa (2007) in a study to compare the perception and daily learning behaviours of Japanese' and New Zealand' students in solving mathematical problems. A pilot study on 50 pre-university students of the same criteria and background was also carried-out. Some amendments were made to suit the students' understanding of the items. Students were not familiar with the words image and figures, and therefore they were omitted and replaced by the more specific words of graphs and diagrams. Two of the items used the words difficulty and troublesome to describe the ease of students in handling images and figures to solve mathematical problems. The latter was taken out after students had responded that in their opinions, both carried the same meaning. The internal reliability factor was 0.72 . The items were divided into four different categories. The first category was aimed to determining the students' preference level of using graphs or diagrams in their daily learning behaviour while the second category was aimed at determining their view on the usefulness of graphs or diagrams in solving mathematical problems. The third category was aimed at determining the students' perception of the difficulty of using of graphs and diagrams in solving mathematical 
problems and the final category was meant to determining their perception of the teacher's behaviour in using graphs or diagrams in solving mathematical problems. Students' preferences were indicated using a 5-point Likert scale $(1=$ Not at all, 2=Slightly, 3=Moderately, 4=Very much and 5=Definitely).

In order to investigate the extent to which students employ graphs as visual information to reason in solving derivative problems, a Visual Reasoning Test consisting of five tasks was constructed; only two of the tasks are discussed in this article. All the tasks were graphaccompanied questions where students must refer to the graphs for solutions. All the tasks were set in accordance with the curriculum outlined by the South Australian Certificate of Education, to which the students were registered. The tasks were examined by two experts in the area for their content validity. In order to examine the distribution of responses from the students, the frequencies and percentages were computed for each part of all the tasks based on the general rubrics shown in Table 1. The rubric was sent to an international expert for its content validity. Students' works were assessed based on 5 categories of $0=$ Not Attempted or No Answer (NA) when the students did not attempt or left the task unanswered; 1 = Incorrect Solution with Invalid or No Reason (IINR) when the students produced incorrect solution and incorrect reason or did not provide any reason at all for the task attempted; $2=$ Correct Solution with No Reason (CNR) when the students managed to arrive at the correct solution but did not provide any reason for carrying out the steps taken; 3 = Correct Solution with Invalid Reason (CIR) when the students managed to arrive at the correct solution but had provided invalid reason; and $4=$ Correct Reason with Valid Reason (CR) when the students managed to get or use the correct solution together and provide a valid reason for the steps taken. The students were also asked to provide qualitative information about the reasons or methods they employed to arrive at the solutions so as to further investigate their thinking, understandings or misconceptions of the graphs.

Table 1

General Rubric for the Visual Reasoning Test

\begin{tabular}{lll}
\hline Point & Code & Description \\
\hline 4 & CR & Correct solution with valid reason \\
3 & CIR & Correct solution with invalid reason \\
2 & CNR & Correct solution with no reason \\
1 & IINR & Incorrect solution with invalid reason / no reason \\
0 & NA & No answer / Not attempted \\
\hline
\end{tabular}

Due to space limitation, only two tasks are discussed in this article. 


\section{Task 1}

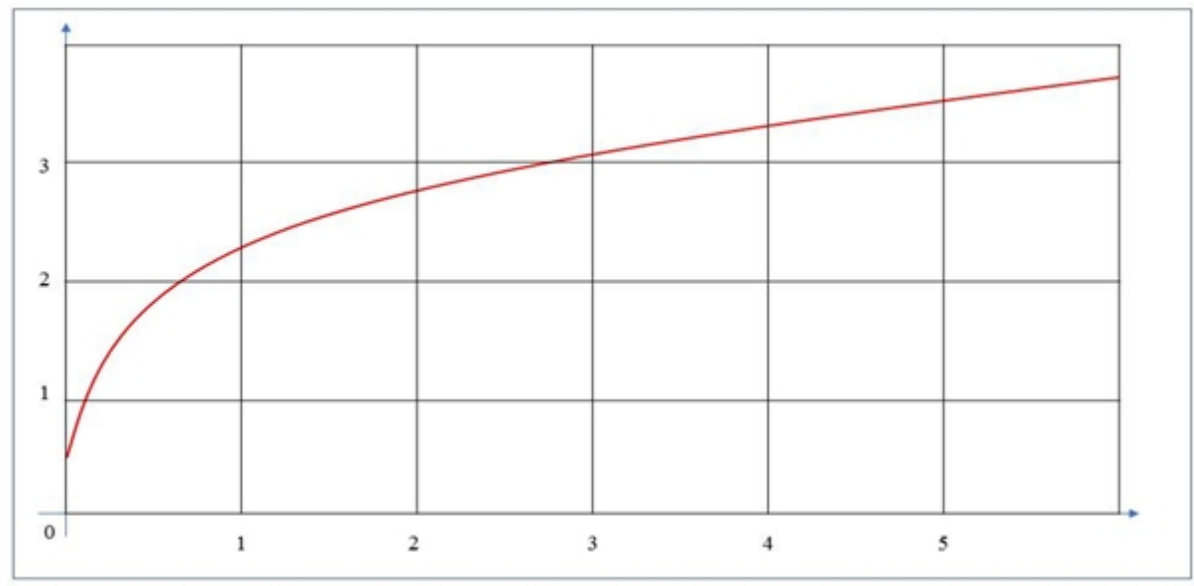

Figure 1. The Cartesian graph for Task 1.

In Task 1, (see Figure 1) students were expected to know the basic properties of functions and the derivation of slopes, starting with the slope of the chord through the slope of tangent and the relationship between them. The students were also expected to compare the numerical values of the slopes by inspecting the shape of the graph of functions. They were also expected to know how to sketch the situations on the graph of functions provided.

\section{Task 2}

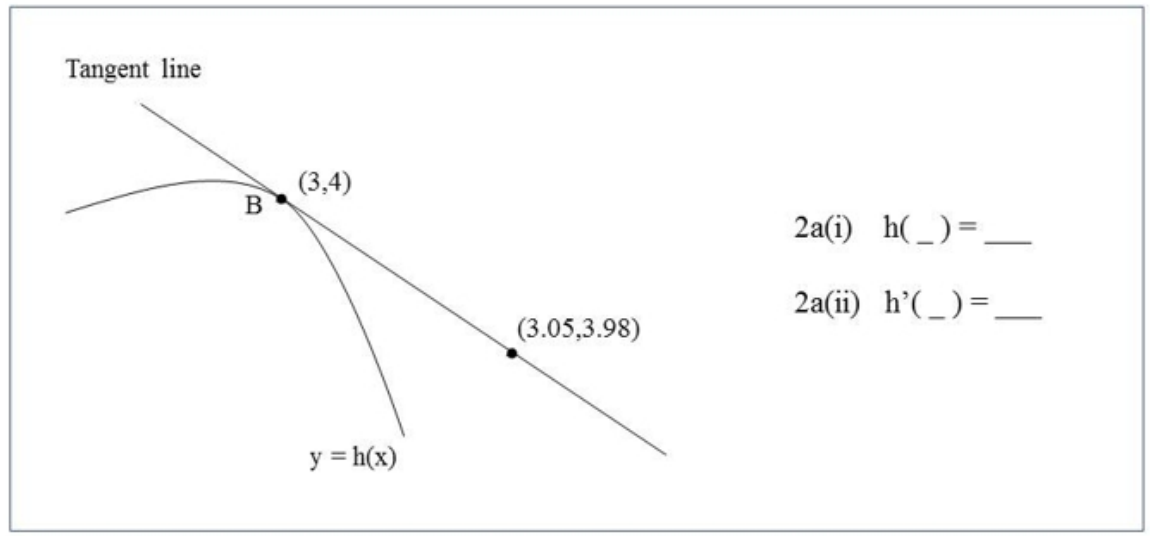

Figure 2. The Cartesian graph for Task 2.

In Task 2, (see Figure 2) students were expected to know the coordinates of the tangent at the point of contact, $\mathrm{B}$, and the slope of the tangent itself. The students were also expected to know the basics of how to calculate the slope of a straight line using two points that lie on the line.

Data collection from both the questionnaires and tasks were completed in separate sessions with the first one lasting for 30 minutes and the second one lasting for 45 minutes. This was to ensure that ample time was allocated for the students to solve the problems. The participants worked individually but with the presence of the researcher. 


\section{Results}

The first research question looks at the students' perception of the use of graphs in the teaching and learning of mathematics in general. Table 2 presents the analysis of the students' preference levels of using graphs or diagrams in their daily learning behaviour. The analysis shows that more than $50 \%$ of the students were in the Definitely and Very Much categories for the first four items while $41.75 \%$ of the students were in the same category for item 5 . For all the items, less than $20 \%$ of the students responded as Slightly or Not at all to indicate their preference levels of very little use of graphs or diagrams when solving mathematical problems. The analysis indicates that the students are very positive in using graphs and diagrams in the classroom, either those in the textbooks or by the teachers. This consequently affects the way they understand or solve mathematical problems. Nevertheless, as shown in the analysis of item 5, the students seemed to be quite reluctant to adopt graphs or diagrams for solving the mathematical problems by themselves. This indicates their low confidence level in drawing/sketching and using graphs or diagrams to solve mathematical problems.

Table 2

The Students' Preference Levels on Using Graphs or Diagrams in Their Daily Learning Behaviour

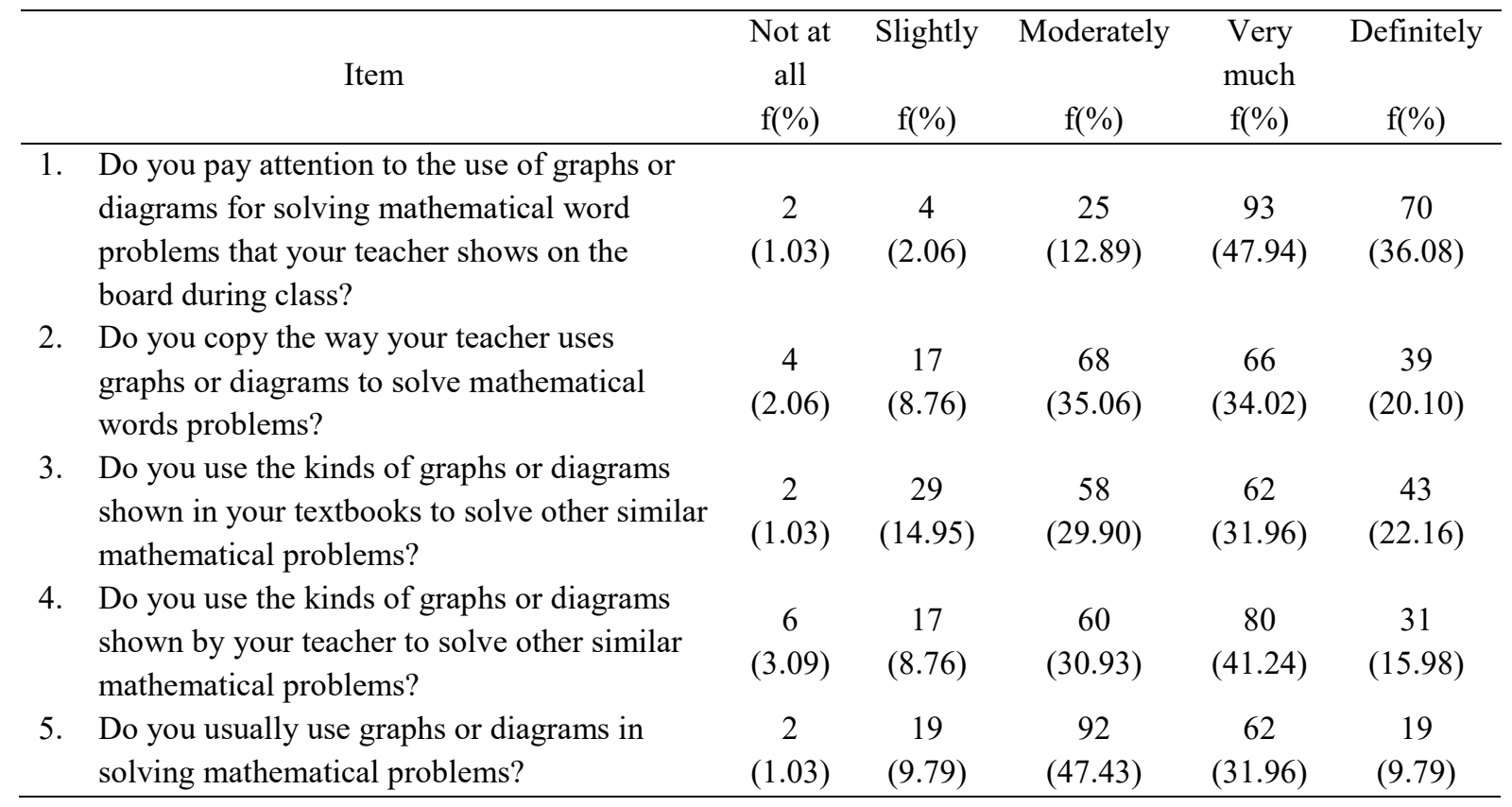

Table 3 displays the results of the analysis on the students' views of the usefulness of graphs or diagrams in solving mathematical problems. The finding revealed that more than $70 \%$ of the students responded that graphs or diagrams are at least Very much useful and helpful for efficiently solving mathematical problems. Only a small portion of less than $7 \%$ of the students either Slightly or Not at all agree with the same statement. The response rates from the students in the analysis showed that the students agree that graphs and diagrams are actually useful for them to efficiently solve mathematical problems. 
Table 3

The Students' View on the Usefulness of Graphs or Diagrams in Solving Mathematical Problems

\begin{tabular}{|c|c|c|c|c|c|c|}
\hline \multirow[t]{2}{*}{ Item } & & \multirow{2}{*}{$\begin{array}{l}\text { Not at } \\
\text { all } \\
\mathrm{f}(\%)\end{array}$} & Slightly & Moderately & \multirow{2}{*}{$\begin{array}{l}\text { Very } \\
\text { much } \\
\mathrm{f}(\%)\end{array}$} & \multirow{2}{*}{$\begin{array}{l}\text { Definitely } \\
\mathrm{f}(\%)\end{array}$} \\
\hline & & & $f(\%)$ & $f(\%)$ & & \\
\hline & $\begin{array}{l}\text { Do you think graphs or diagrams are helpful } \\
\text { for efficiently solving mathematical word } \\
\text { problems? }\end{array}$ & $\begin{array}{c}0 \\
(0)\end{array}$ & $\begin{array}{c}4 \\
(2.06)\end{array}$ & $\begin{array}{c}39 \\
(20.10)\end{array}$ & $\begin{array}{c}81 \\
(41.76)\end{array}$ & $\begin{array}{c}70 \\
(36.08)\end{array}$ \\
\hline 7. & $\begin{array}{l}\text { Do you think it is good to use graphs or } \\
\text { diagrams in solving mathematical word } \\
\text { problems? }\end{array}$ & $\begin{array}{c}2 \\
(1.03)\end{array}$ & $\begin{array}{c}10 \\
(5.15)\end{array}$ & $\begin{array}{c}45 \\
(23.20)\end{array}$ & $\begin{array}{c}60 \\
(30.93)\end{array}$ & $\begin{array}{c}77 \\
(39.69)\end{array}$ \\
\hline 8. & $\begin{array}{l}\text { Do you think graphs or diagrams help you to } \\
\text { figure out how to solve mathematical word } \\
\text { problems? }\end{array}$ & $\begin{array}{c}0 \\
(0)\end{array}$ & $\begin{array}{c}4 \\
(2.06)\end{array}$ & $\begin{array}{c}52 \\
(26.80)\end{array}$ & $\begin{array}{c}85 \\
(43.82)\end{array}$ & $\begin{array}{c}53 \\
(27.32)\end{array}$ \\
\hline
\end{tabular}

The analysis of the students' perception of the difficulty of using graphs or diagrams when solving mathematical problems is shown in Table 4. The overall finding shows that less than half of the students responded to Definitely or Very much to all the items in this category, indicating that the majority of the students did not know how to construct the graphs or diagrams and that it was easy for them to use graphs or diagrams to help them solve mathematical problems. Meanwhile, less than $50 \%$ of the students seemed to know how to construct graphs or diagrams for solving mathematical word problems and said that it was easy to use or draw graphs or diagram to solve mathematical word problems. A small minority of the students also knew the types of graphs or diagrams that are helpful in solving mathematical problems. The analysis indicates that students lacked the confidence when it came to the situation where they had to make use of the diagrams or graphs provided in the tasks to solve mathematical problems or when they needed to construct or draw graphs or diagrams to help them find the solution.

Table 4

The Students' Perception on the Difficulty of Using Graphs or Diagrams in Solving Mathematical Problems

\begin{tabular}{|c|c|c|c|c|c|c|}
\hline & \multirow[t]{2}{*}{ Item } & \multirow{2}{*}{$\begin{array}{l}\text { Not at } \\
\text { all } \\
\mathrm{f}(\%)\end{array}$} & \multirow{2}{*}{$\begin{array}{l}\text { Slightly } \\
\mathrm{f}(\%)\end{array}$} & \multirow{2}{*}{$\begin{array}{l}\text { Moderately } \\
\mathrm{f}(\%)\end{array}$} & \multirow{2}{*}{$\begin{array}{l}\text { Very } \\
\text { much } \\
f(\%)\end{array}$} & \multirow{2}{*}{$\begin{array}{l}\text { Definitely } \\
\text { f(\%) }\end{array}$} \\
\hline & & & & & & \\
\hline 9. & $\begin{array}{l}\text { In general, do you know how to construct } \\
\text { graphs or diagrams for solving mathematical } \\
\text { word problems? }\end{array}$ & $\begin{array}{c}4 \\
(2.06)\end{array}$ & $\begin{array}{c}16 \\
(8.25)\end{array}$ & $\begin{array}{c}90 \\
(46.39)\end{array}$ & $\begin{array}{c}72 \\
(37.11)\end{array}$ & $\begin{array}{c}12 \\
(6.19)\end{array}$ \\
\hline 10. & $\begin{array}{l}\text { How easy is it for you to use graphs or } \\
\text { diagrams in solving mathematical word } \\
\text { problems? }\end{array}$ & $\begin{array}{c}4 \\
(2.06)\end{array}$ & $\begin{array}{c}19 \\
(9.79)\end{array}$ & $\begin{array}{c}95 \\
(48.97)\end{array}$ & $\begin{array}{c}64 \\
(33.99)\end{array}$ & $\begin{array}{c}12 \\
(6.19)\end{array}$ \\
\hline 11. & $\begin{array}{l}\text { Do you know the types of graphs or } \\
\text { diagrams that are helpful in solving different } \\
\text { kinds of mathematical word problems? }\end{array}$ & $\begin{array}{c}8 \\
(4.12)\end{array}$ & $\begin{array}{c}19 \\
(9.79)\end{array}$ & $\begin{array}{c}107 \\
(55.16)\end{array}$ & $\begin{array}{c}50 \\
(25.78)\end{array}$ & $\begin{array}{c}10 \\
(5.15)\end{array}$ \\
\hline 12. & $\begin{array}{l}\text { How easy is it for you to draw graphs or } \\
\text { diagrams by yourself for solving } \\
\text { mathematical word problems? }\end{array}$ & $\begin{array}{c}2 \\
(1.03)\end{array}$ & $\begin{array}{c}45 \\
(23.20)\end{array}$ & $\begin{array}{c}106 \\
(54.64)\end{array}$ & $\begin{array}{c}35 \\
(18.04)\end{array}$ & $\begin{array}{c}6 \\
(3.09)\end{array}$ \\
\hline
\end{tabular}


Table 5 displays the students' perception of their teacher's behaviours in using graphs or diagrams to solve mathematical problems. It can be seen that the majority, or more than $70 \%$, of the students were at least at Very much levels. In fact, they were very positive about their teachers' use the graphs or diagrams to efficiently solve mathematical problems and explain to them how to solve mathematical word problems. About $73.71 \%$ of the students stated that the graphs or diagrams that their teacher use to show them how to solve mathematical problems Definitely or Very much help them understand how those problems are solved. On the same note, the majority $(67.01 \%)$, of the students stated that their teachers actually encouraged and taught them how to use graphs or diagrams to solve mathematical word problems. Less than 10\% responded either Not at all or Slightly for this category of items. According to the analysis, the types of graphs and diagrams and how the teachers make use of them in their teaching play an important role in making the students understand mathematical concepts and the method they employ to solve the mathematical problems.

Table 5

The Students' Perception on their Teacher's Behaviour in Using Graphs or Diagrams in Solving Mathematical Problems

\begin{tabular}{|c|c|c|c|c|c|c|}
\hline & \multirow[t]{2}{*}{ Item } & \multirow{2}{*}{$\begin{array}{l}\text { Not at } \\
\text { all } \\
\mathrm{f}(\%)\end{array}$} & \multirow{2}{*}{$\begin{array}{l}\text { Slightly } \\
\text { f(\%) }\end{array}$} & \multirow{2}{*}{$\begin{array}{l}\text { Moderately } \\
\mathrm{f}(\%)\end{array}$} & \multirow{2}{*}{$\begin{array}{l}\text { Very } \\
\text { much } \\
\mathrm{f}(\%)\end{array}$} & \multirow{2}{*}{$\begin{array}{c}\text { Definitely } \\
\mathrm{f}(\%)\end{array}$} \\
\hline & & & & & & \\
\hline 13. & $\begin{array}{l}\text { Do you think your mathematics teachers use } \\
\text { graphs or diagrams to efficiently solve } \\
\text { mathematical word problems? }\end{array}$ & $\begin{array}{c}2 \\
(1.03)\end{array}$ & $\begin{array}{c}6 \\
(3.09)\end{array}$ & $\begin{array}{c}31 \\
(15.98)\end{array}$ & $\begin{array}{c}64 \\
(32.99)\end{array}$ & $\begin{array}{c}91 \\
(46.91)\end{array}$ \\
\hline 14. & $\begin{array}{l}\text { Do your mathematics teachers use graphs or } \\
\text { diagrams to explain how to solve } \\
\text { mathematical word problems? }\end{array}$ & $\begin{array}{c}2 \\
(1.03)\end{array}$ & $\begin{array}{c}2 \\
(1.03)\end{array}$ & $\begin{array}{c}41 \\
(21.13)\end{array}$ & $\begin{array}{c}80 \\
(41.24)\end{array}$ & $\begin{array}{c}69 \\
(35.57)\end{array}$ \\
\hline 15. & $\begin{array}{l}\text { Do the graphs or diagrams that your teachers } \\
\text { use to show how to solve mathematical word } \\
\text { problems help you to understand how those } \\
\text { problems can be solved? }\end{array}$ & $\begin{array}{c}0 \\
(0)\end{array}$ & $\begin{array}{c}2 \\
(1.03)\end{array}$ & $\begin{array}{c}49 \\
(25.26)\end{array}$ & $\begin{array}{c}75 \\
(38.66)\end{array}$ & $\begin{array}{c}68 \\
(35.05)\end{array}$ \\
\hline 16. & $\begin{array}{l}\text { Do your mathematics teachers teach your } \\
\text { class how to use graphs or diagrams in } \\
\text { solving mathematics word problems? }\end{array}$ & $\begin{array}{c}2 \\
(1.03)\end{array}$ & $\begin{array}{c}10 \\
(5.15)\end{array}$ & $\begin{array}{c}45 \\
(23.20)\end{array}$ & $\begin{array}{c}64 \\
(32.99)\end{array}$ & $\begin{array}{c}73 \\
(37.63)\end{array}$ \\
\hline 17. & $\begin{array}{l}\text { Are you told or encouraged by your } \\
\text { mathematic teachers to use graphs or } \\
\text { diagrams in solving mathematics word } \\
\text { problems? }\end{array}$ & $\begin{array}{c}0 \\
(0)\end{array}$ & $\begin{array}{c}17 \\
(8.76)\end{array}$ & $\begin{array}{c}47 \\
(24.23)\end{array}$ & $\begin{array}{c}72 \\
(37.11)\end{array}$ & $\begin{array}{c}58 \\
(29.90)\end{array}$ \\
\hline
\end{tabular}

The second research question seeks to investigate the extent students employ graphs as visual information to reason in solving derivative problems. The students worked solutions were classified by the correct or incorrect solutions together with the reasons they provided if any. Figure 3 displays the percentages of students' types of solutions for item 1 . The analysis shows that a large majority of the students managed to get the correct answers for the tasks although some supplied invalid reason or did not provide any reasons at all. Meanwhile, a small portion of less than $40 \%$ of the students solved the problem incorrectly and came out with invalid reasons. For most of the items, less than $25.26 \%$ of the students did not attempt to solve 
the problems at all. The analysis indicates that the majority of the students were able to read and understand the information about the function and its related characteristics of the derivative from the given graph.

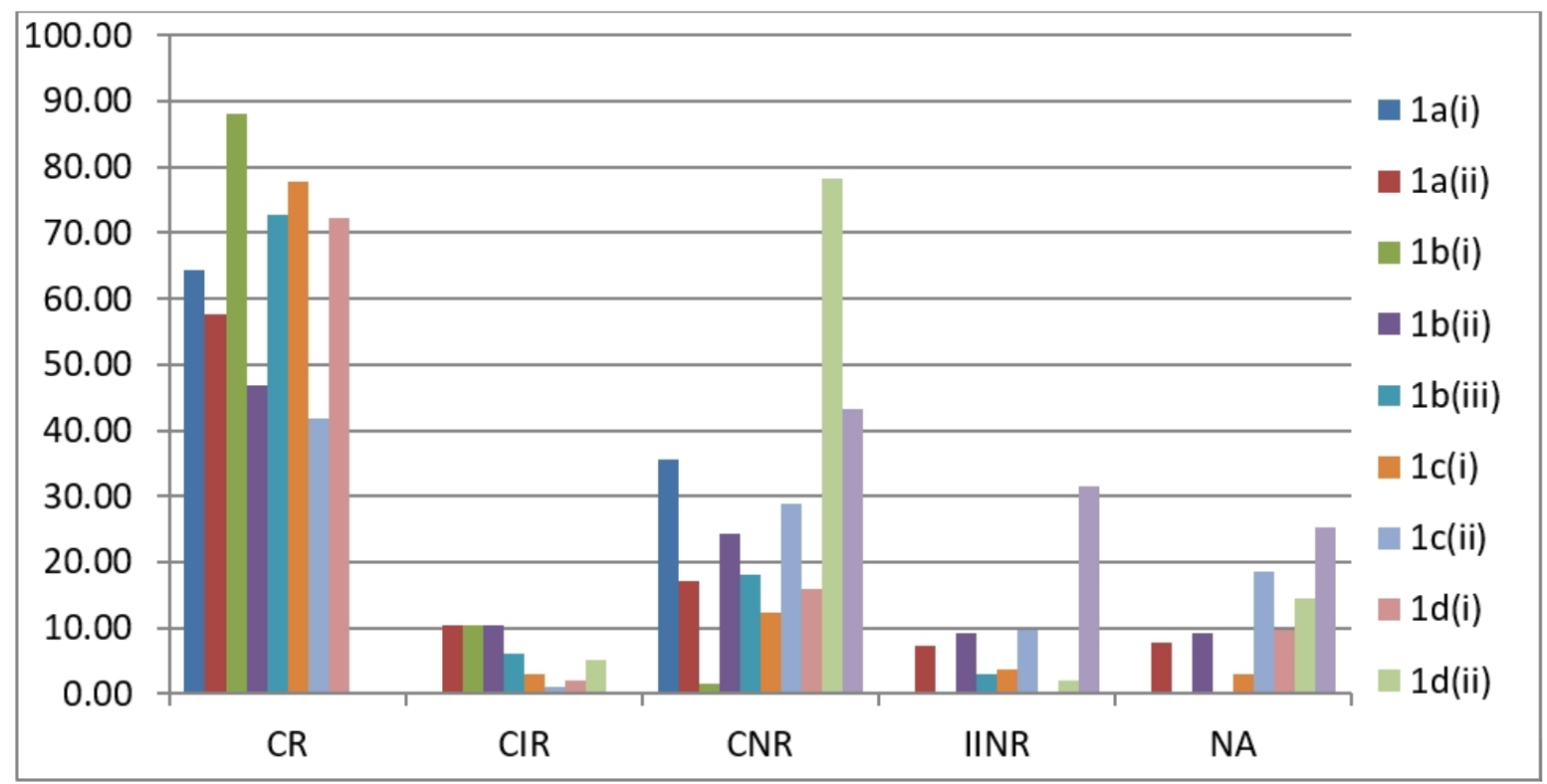

Figure 3. The distribution of responses for Task 1.

Figure 4 displays the percentages of the types of students' solution for Task 2. A total of approximately $85 \%$ of the students managed to solve the problem correctly regardless of whether they provided correct reasons or not, while less than half of them were in the same category for Task 2(a)(ii). About half of the students produced incorrect solution and together with incorrect reasons or did not provide any reason at all. Less than $7 \%$ of the students did not attempt to solve the tasks at all. Once again, the analysis shows that students were able to read the information from the graph of functions although only a smaller portion of them managed to provide valid reasons.

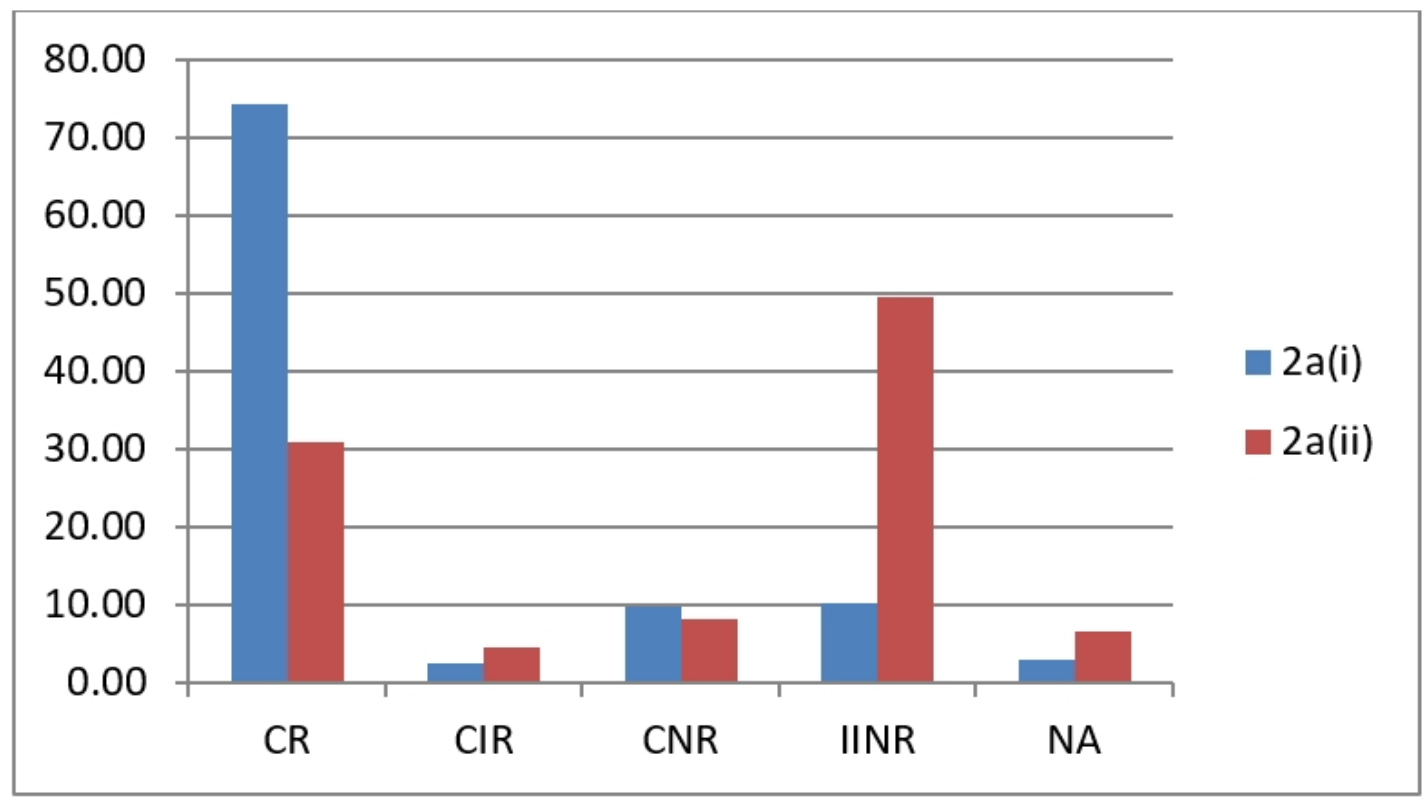

Figure 4. The distribution of responses for Task 2. 
The last research question looks for the correlation between the students' perceptions of the use of graphs and their actual utilisation of graphs in solving derivative problems. As displayed in Figure 5, there is a positive correlation between the students' mean values of the use level of visual representation and their mean values for Visual Reasoning Test. In general, the students were able to use graphs to understand the properties of functions and their related derivative as how they perceived the use level of graphs in their daily learning of mathematics. Specifically, it can be seen from the graph that there are three distinguished patterns describing how the students' usage level and their actual visual reasoning ability are related. The first region with higher VRUL $(>4.3)$ tends to have higher VRT than the regions with lower VRUL. Among the region with lower VRUL values, between 3 and 4.3, a small difference in VRUL reflects a significant increase of difference in the VRT. On the other hand, the region with the lowest VRUL values of less than 3 displays a relatively small increase in the VRT upon a small difference in the VRUL.

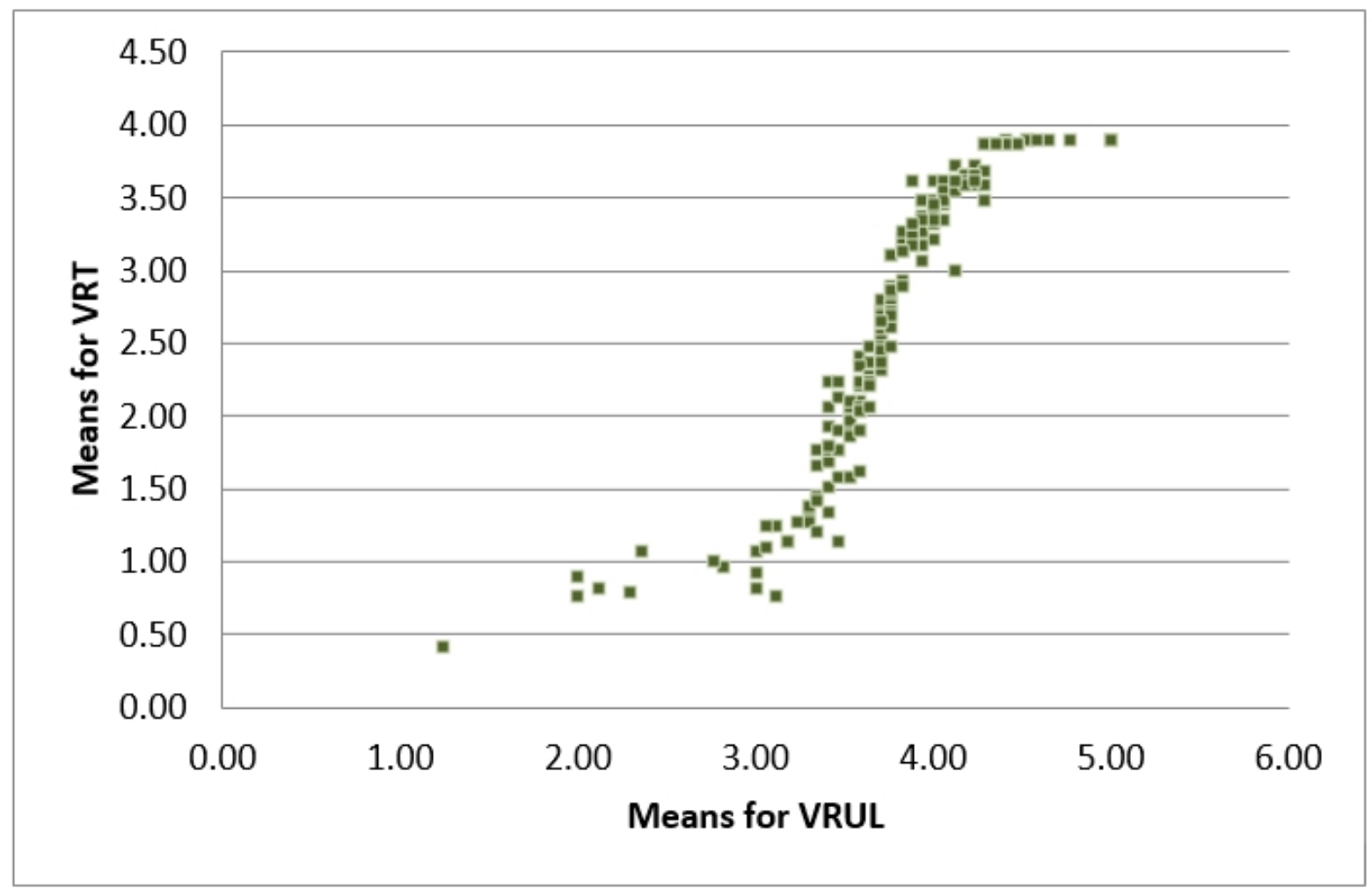

Figure 5. Distribution of the students' means for the usage level of visual representation and the means for the Visual Reasoning Test.

The scatterplot was subjected to linear regression. The relationship between the mean values of VRUL and the mean values of VRT can be described algebraically by the equation: $y=0.55 x+1.31$, with a positive coefficient of the correlation value of $r=0.879$. The value 0.55 indicates that for every additional value in VRUL as an independent variable, it is expected that the dependent variable VRT values to increase by an average of 0.55 . Moving to the left or to the right along the $x$-axis by an amount that represents one unit change in the VRUL, the fitted line will rise by 0.55 unit points. However, these VRUL and MVT values were obtained 
from the pre-university students at one college. Therefore, the relationship is only valid within these intervals of data range. Hence, no prediction is to be made outside the data range.

\section{Discussion}

Pre-university students have always portrayed calculus, specifically differential calculus as one of the difficult topics in mathematics. They often misunderstand the notion of function, its properties and related derivative graphically. Most of the students are able to easily manipulate the algebraic rules on differentiation, be it the chain rule, product rule, quotient rule, etc. The visual approach seems to be manageable when they need to just read information; however, as the tasks get more complicated, the majority of the students tend to incorrectly extract or make meaning of the information. Researchers have suggested that the more complicated the tasks assigned to students, the more cognitive efforts are required in order to understand the information embedded in the graphs and diagrams (Alacaci, Lewis, O'Brien \& Jiang, 2011; Sharma, 2013; Uesaka \& Manalo, 2011).

The results also indicated that the students were positive towards the use of graphs and diagrams in assisting them in their learning and solving mathematical problems (Uesaka \& Manalo, 2011). Therefore, teachers should modify their method of teaching by using more visually represented materials in classrooms so as to gain their students' attention and make understanding of concepts much easier. At the same time, the curriculum developers can also make use of the results by including more graph-based or diagram-based approaches starting from the lower level at primary schools and throughout all levels of educations.

To summarise, it is clear from the results of the study that most of the students are encouraged to use graphs and diagrams in their mathematical learning although the actual action stated is otherwise. Therefore, they need to be exposed to alternative methods of understanding concepts and classroom instructions. Much attention should be focussed on cultivating student's ability to use graphs as visual reasoning tools. If this is not implemented, students will likely be progressively complacent with their procedural methods of solutions especially those who manage to arrive at the correct solution and may not achieve their mathematical problem solving experiences at a higher level of education. It is hoped that the findings of this study will generate more interest in this research area and expand the literature of students' visual reasoning ability and conceptual understanding of functions and their derivatives to enhance teachers' awareness of their students' thought processes and visual reasoning skills. There is also a need to look into students' ability to construct appropriate and detailed graphs and diagrams to solve particular problems. 


\section{References}

Alacaci, C., Lewis, S., O’Brien, G., \& Jiang, Z. (2011). Pre-Service Elementary Teachers' Understanding of Graphs. Eurasia Journal of Mathematics, Science and Technology Education, 7(1), 3-14.

Asiala, M., Cottrill, J., Dubinsky, E., \& Schwingendorf, K. (1997). The Development of Students' Graphical Understanding of the Derivative. Journal of Mathematical Behavior 16(4), 399-431.

Aspinwall, L., Shaw, K., \& Presmeg, N. (1997). Uncontrollable mental imagery: Graphical connections between a function and its derivative. Educational Studies in Mathematics, 33(3), 301-317.

Baker, B., Cooley, L., \& Trigueros, M. (2000). A Calculus Graphing Schema. Journal for Research in Mathematics Education, 31(5), 557-578.

Borgen, K. \& Manu, S.S. (2002). What do students really understand? Journal of Mathematical Behavior, 21, 151-165.

Ball, D. L., Hoyles, C., Jahnke, H. N., \& Movshovitz-Hadar, N. (2002). The teaching of proof. In L. I. Tatsien (Ed.), Proceedings of the international congress of mathematicians (pp. 907-920). Beijing: Higher Education Press.

Haapasalo, L. \& Kadijevich, Dj. (2000). Two types of mathematical knowledge and their relation. Journal für Mathematik-Didaktik, 21(2), 139-157.

Hanna, G., \& Jahnke, H. N. (1996). Proof and proving. In A. Bishop, K. Clements, C. Keitel, J. Kilpatrick \& C. Laborde (Eds.), International handbook of mathematics education (pp. 877-908). Dordrecht, The Netherlands: Kluwer.

Kamii, C., \& Dominck, A. (1998). The harmful effects of algorithms in grades 1-4. In L. J. Morrow, \& M. J. Kenney (Eds.), The teaching and learning of algorithms in school mathematics: 1998 yearbook (pp. 130-140). Reston, VA: The National Council of Teachers of Mathematics.

Kosslyn, S. M. (1994). Elements of Graph Design. New York: W.H. Freeman \& Co Ltd.

Larkin, J.H., \& Simon, H.A. (1987). Why a diagram is (sometimes) worth ten thousand words. Cognitive Science, 11, 65-99.

Lohse, G. L. (1993). A cognitive model for understanding graphical perception. HumanComputer Interaction, 8, 353-388.

Monk, G. S. (1994). Students' Understanding of Functions in Calculus Courses. Humanistic Mathematics Network Journal, 9, 21-27.

Orton, A. (1983). Students' Understanding of Differentiation. Educational Studies in Mathematics, 14(3), 235-250.

Ratwani, R.M., Trafton, J. G., \& Boehm-Davis, D. A. (2008). Thinking graphically: connecting vision and cognition during graph comprehension. Journal of Experimental Psychology: Applied, 14(1), 36-49.

Sharma, S. (2013). Assessing Students' Understanding of Tables and Graphs: Implications for Teaching and Research. International Journal of Educational Research and Technology, 4(4), 51-70.

Schoenfeld, A. H. (1992). Learning to think mathematically: Problem solving, metacognition, and sense making in mathematics. In D. A. Grows (Ed.), Handbook of research on mathematics teaching and learning (pp. 334-370). New York: Macmillan

Stahley, J. R. (2011). Students' qualitative understanding of the relationship between the graph of a function and the graphs of its derivatives. Unpublished Master's Thesis. The University of Maine, USA.

Stylanides, A. J. (2007). Proof and proving in school mathematics. Journal for Research in Mathematics Education, 38(3), 289-321. 
Tiwari, T. K. (2007). Computer Graphics as an Instructional Aid in an Introductory Differential Calculus Course. International Electronic Journal of Mathematics Education, 2(1), 32-48.

Ubuz, B. (2007). Interpreting a graph and constructing its derivative graph: stability and change in students' conceptions. International Journal of Mathematical Education in Science and Technology, 38(5), 609-637.

Uesaka, Y., \& Manalo, E. (2011). Task-related factors that influence the spontaneous use of diagrams in maths problems. Applied Cognitive Psycholog, 26, 251-260.

Uesaka, Y., Manalo, E., \& Ichikawa, S. (2007). What kinds of perceptions and daily learning behaviors promote students' use of diagrams in mathematics problem solving? Learning and Instruction, 17, 322-335.

Waller, R. (1981). Understanding netwotk diagrams. Paper presented at the Annual Meeting of the American Educational Research Association, Los Angelos, April 1981

Zandieh, M. J. (2000). A Theoretical Framework for Analyzing Student Understanding of the Concept of Derivative. CBMS, Issues in Mathematics Education. (103-127) Providence, RI: American Mathematical Society.

Zimmerman, W. (1991). Visual Thinking in Calculus. In Z. Cunningham (Ed.), Visualization in Mathematics. (Notes \# 19, 127-137), Washington, DC: Mathematics Associations of America. 